\title{
Market acceptability of dried dates at the unripe "Bisr" stage in United Arab Emirates
}

\author{
Berhanu Degefa*, Safdar Muhammad, Eihab Fathelrahman \\ Department of Agribusiness, College of Food and Agriculture, United Arab Emirates University, Al Ain, P.O. Box 15551, United Arab Emirates
}

\section{A B S T R A C T}

\begin{abstract}
The dates produce form of dates fruit considered in this study is called "Bisr", which is unripe fruit that can be harvested and dried to capture several sensory and economic value-added advantages compared to the ripe date. In this study, the product's sensory characteristics are added to the socio-economic characteristics of consumers to understand the factors or independent variables that affect the changes in the dependent variable, willingness to pay (WTP) of consumers. The objective of the analysis is to explore the consumers' perception, acceptance and their attitude towards the "Bisr" and to identify the characteristics of the final product that are important to the overall marketability of the product. The survey data shows that over two-third or $70 \%$ of the 276 respondents have reported that they would buy "Bisr" if the commodity becomes commercially available. Overall marketability is affected by both respondents' socio-economic characteristics and their responses to the sensory questionnaire. The result showed the presence of an opportunity to develop a "Bisr" by adding economic value to date and diversify the sources of benefits for both producers and consumers from date production in the UAE.
\end{abstract}

Keywords: Dates fruit; Drying; Market acceptability

\section{INTRODUCTION}

The production of date palm (Phoenix dactylifera L.) is socially, culturally and economically significant for the United Arab Emirates (UAE). The exact origin of the date palm is lost in antiquity. However, it is certain that the date palm is among the oldest plants cultivated on Earth (as early as 4000 B.C.) and widely planted in hot and dry climate of Asia, Middle East, Africa and Arabian Peninsula (Nasir et al., 2015). Historically, it has been an important food and sources of nutritious diet for the people of the dryland regions, especially the Middle East and North African countries, and plays an important role in their day-to-day cultural life and hospitality (Al-Farsi et al., 2005; Shafiei et al., 2010). Dates are widely consumed in the UAE and other Arab states of Persian Gulf countries. According to Ismail et al. (2006) quoated in Nasir et al (2015)). The average per capita consumption of dates in the United Arab Emirates and Oman was estimated at 115 and 165 grams/day, respectively, giving an average of $\sim 140$ grams/day. Chandrasekaran and Bahkali (2013) indiacted that the nutritional value of dates is due to their high content of sugar, potassium, calcium, magnesium, iron as well as vitamins (B1, B2) and Niacin. The authors further noted that the sugare content of dates is around $50-60 \%$ while the amount of potassium is 2.5 times more than banana. Referring to some earlier literature, Al-Orf et al. (2012) also indicated that nutritionally, dates is an ideal high energy food due to its high content of sugar. The authors also indicated that date fruit is used in folk medicine to treat the different infectious diseases probably because of their antibacterial ability, immuneomodulatory activity and antifungal property.

Date fruits are consumed at three developmental stages - "Bisr", Rutab and Tamar. Currently, very small amounts of date fruits are consumed at the firm and crunchy "Bisr" stage (or Khalaal, 50\% moisture), small amounts at the Rutab or ripe stage (30-35\% moisture) while the main portion is consumed as fresh or dried pitted dates at the Tamer stage (10-30\% moisture) (Sami et al., 2017). Majority of the date fruits produce is consumed in the UAE with little or no processing while a small amount being processed into syrups and pastes. Overproduction of dates under the situation of limited processing capacity leads to a huge lose especially for low quality grade fruits. According to Sami et al. (2017), globally major losses amounting

\footnotetext{
*Corresponding author:

Berhanu Degefa, Department of Agribusiness, College of Food and Agriculture, United Arab Emirates University, P.O. Box 15551, Al Ain, United Arab Emirates. E-mail: berhanu.adenew@uaeu.ac.ae
} 
to some 2 million tons per year occur in the process of harvesting, storage, conditioning, and processing of dates. Due to the high sugar content of dates consumed at a Tamer sateg, there is currently an increasing concern about its contribution to the prevalence of diabetes and obesity in the UAE. Thus, it will be beneficial to utilize high fibercontaining date varieties at the "Bisr" stage as functional ingredients in foods.

The UAE is one of the major date producer countries. According to El-Juhany (2010), the United Arab Emirates is recognized among the leading date palm cultivator countries, having some 42 million date palm trees. Khaleej Times news report (2011) referring to the Food and Agriculture Organization shows that in 2008 global date production was 7.1 million tonnes out of which 3 million tonnes were produced by the top 20 date producing nations of the world. Egypt, Iran, Saudi Arabia and the United Arab Emirates were the top four producers. The report also indicated that the UAE's total production of 755 thousand tonnes dates accounted for 11 per cent of global production. The Food and Agricultural Organization's statistical database (FAOSTAT) (FAO, 2016) shows that the UAE's average annual date production for the years $1994-2014$ was 519,422 tonnes. Production significantly increased from the year 1998 onward, and stabilized around 750 thousand tonnes for a decade reaching a peak of 830 thousand tonnes in 2010. Production has declined afterwards (see Fig. 1). Considering the average level of production of the years 1994 - 2014, the $\mathrm{UAE}$ is the $6^{\text {th }}$ major producer preceded by Egypt, Iran, Saudi Arabia, Iraq and Pakistan. Dates is the $4^{\text {th }}$ major crop produced in the UAE next to vegetables, melons and fruits.

The UAE ranked a third in the global trade of dates in 2009 (Khaleej Times, 2011). UAE takes 33 per cent share of the world's export of dates followed by Iraq at 22 per cent. The two countries accounted for more than half of the global exports of dates. The UNFAO database (FOSTAT) shows

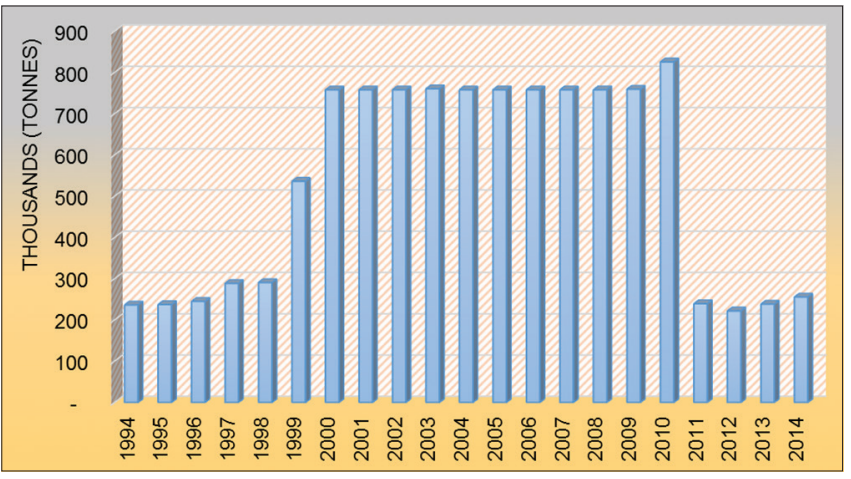

Fig 1. Dates Production in the United Arab Emirates (1994-2014). Source: Based on the Food and Agriculture Organization database - FAOSTAT (FAO, 2016). that the UAE's date export increased from about 200,000 metric tonnes in 1995 to close to 300,000 metric tonnes in 2005. However, the export volume dropped to below 100,000 metric tonnes annually during 2009 -2012. As for imports, UAE's imports of dates constituted 31.5 per cent of the global share, second to India, which possessed only a slightly larger share of 31.6 per cent (Khaleej Times, 2011). However, the overall trend in UAE's exports of dates has been volatile.

El-Juhany (2010) discusses some of the challenges that face the dates production system. These include lack of adequate research and development in pest and disease control, availability of only few high-quality date varieties, poor methods of harvesting, poor processing and packaging at the farm gate. In addition, poor irrigation and water management that lead to the overuse of limited groundwater and high cost of production are cited as the problems faced. El-Juhany (2010) suggested the need for rehabilitation of palm trees in the Arab countries and stressed that such rehabilitation is crucial. The author recommended that it is essential to strengthen the date production industry through improved management of the plantation, harvesting, processing and marketing.

In the UAE and other date palm producer countries, in order to maximize the benefit of use of dates by consumers in the domestic market as well as to capture the economic advantages form export market, producers and marketing agencies will have to focus on the demands of their potential customers. Innovative activities in value-additions and facilitating market outlets for food product are among the strategies to enhance the economic benefits from production and consumption of dates. Chandrasekaran and Bahkali (2013) noted that date palm fruit is an ideal substrate for deriving a range of valueadded products in food and nutraceutical industries in the future employing bioprocessing technologies which have immense scope for application in the valorization of date fruit by-products and wastes. Literature on consumer sciences have abundantly discussed the behavioral and decision making processes involved in the acceptance of food and other products by consumers. The conclusion drawn in several studies made is that the knowledge of consumers' perception, attitude and reaction to products needs to be the integral aspect of the development of product marketing strategy. Many studies that looked at the factors that affect food product acceptance by consumers and product marketability have well explained the role of sensory quality as one of the major determinants. The sensory quality is recognized to be a key factor that influences consumers' food acceptance because consumers seek a food with certain sensory characteristics. In this respect, Costell et al. (2010), for 
instance, concluded that the acceptance of a food product will depend on whether it responds to consumer needs and on the degree of satisfaction provides. The authors further noted that the process by which man accepts or rejects food is of a multi-dimensional nature. In terms of methodological approach, Costell et al. (2000), Jaeger et al. (2003), Santa Cruz et al. (2002), Tenenhaus et al. (2005) and Rodbotten et al. (2009) quoted in Costell et al. (2010, p6) have acknowledged that because of the fact that knowing exactly what consumers perceive is difficult, the main goal of studies about acceptability or preference is usually to establish the relationship between the intensity of perceptible attributes and degree of acceptance. Lusk et al. (2014) noted that there is an evolving trend or a paradigm shift about the factors that are thought to influence consumers in accepting new food technologies. They mentioned that whereas the early researches focused on risk perception of consumers, in more recent times research has turned to investigating the role of emotions, moral judgments, and worldviews.

The paper is based on a research project implemented at the United Arab Emirates University (UAEU) that aims at creating, testing and introducing a new way of processing - drying, preserving and availing date fruits to consumers. The "Bisr" dried fruit needs to be evaluated in terms of consumers' acceptance, marketability and success in creation of its sustainable market. This study, therefore, focuses on evaluating the consumers' perception, acceptance and their attitude towards the "Bisr". Such objective will be achieved through product taste, quality analysis and investigation of factors that affect the consumers' willingness to pay (W'TP) or buy the product. A consumer acceptance test provides information about the preference for and how the developed products are perceived by consumers. The evaluation was conducted in partitioned sensory evaluation booths at the UAE University. The panelists have rated the appearance, color, aroma, taste, flavor, texture and overall acceptance of "Bisr" samples.

The purpose of the analysis of consumers' perception, acceptance and their attitude towards the "Bisr" is to identify the characteristics of the final product that are important to the overall liking of the product. The objectives of this paper are:

1. To describe the socio-demographic features of the potential consumer market of the dried dates fruit "Bisr" included in the sample survey.

2. To identify the characteristics of the final product that are important to the overall liking or acceptance of consumers.

3. To identify the factors that influence the acceptance and marketability of "Bisr" as a new value-added fruit product.
4. To draw policy recommendations towards supporting value-addition and marketing of date to contribute reduction of the date palm degradation in UAE.

\section{MATERAILS AND METHODS}

The methodology section provides the dates "Bisr" samples preparation, Sensory evaluation and specification of model for the analysis of consumer's willingness to pay (WTP) for dates "Bisr".

\section{Dates "Bisr" samples and preparation}

Freshly harvested "Bisr" from the UAE date variety called Neghal was procured from the College of Food and Agriculture's farm at Al-Foah in the UAE. These variety was selected based on the lack/absence of bitterness. The date fruits were packed in ventilated plastic boxes and transported for the experimental studies. The "Bisr" date fruits were sorted, pitted, washed, blanched and used for the drying experiments. The "Bisr" date was steamblanched for 3 minutes and then loaded on to stainless steel trays. The date was also sun-dried.

\section{Sensory evaluation}

The future of the "Bisr" functional food depends on consumers' acceptance and creating markets for the product. The proposed activity mainly focused on the consumers' perception, acceptance and their attitudes towards the "Bisr". The objective is achieved through sensory analysis and identifying factors affecting consumers' willingness to buy or pay for the product. A consumer acceptance test provided information regarding preference for and how the developed products are perceived by consumers. The evaluation took place in partitioned sensory evaluation booths at the UAE University in $\mathrm{Al}$ Ain city. The panelists who participated in the evaluation rated the appearance, color, aroma, taste, flavor, texture and overall acceptance using a 9-point hedonic scale $(1=$ dislike very much and $9=$ like very much). A descriptive analysis to reveal what characteristics of the final product are important to the overall liking or acceptance of consumers was included. The date product was evaluated by a panel using descriptive sensory profiling guideline in the sensory laboratory of the UAE university.

\section{Consumers' acceptance model specification}

The consumers' acceptance and attitude was measured by conducting a comprehensive survey and organizing focus group meetings of the sample consumers drawn from the UAEU university students, faculty and staff, as well as household members in Al Ain city. The survey included questions on awareness about "Bisr", factors that respondents consider when buying, quality preferences, and 
the price they are willing to pay for other desired attributes. The proposed activity will help to identify target market for "Bisr" and provide products according to the market needs and preferences. The socio-economic and demographic characteristics of consumers is also assessed.

An econometric model was developed to analyze the factors that influence consumers' decision to purchase "Bisr" if commercially made available. For this purpose, a logistic regression model, is found to be an appropriate model to fit to the survey data. The rational for selecting this model is the fact that the response variable (i.e. response of the respondents regarding their attitude towards acceptability of "Bisr" if commercially produced) is a binary one.

From among many different methods of computing an $\mathrm{R}^{2}$ for logistic regression, the Cox and Snell (1989) and Nagelkerke R Square are employed here. The SPSS software used for this data analysis reports the Cox-Snell R square and Nagelkerke R Square measures in the binary logistic regression.

The linear logistic model assumes a dichotomous dependent variable $\mathrm{Y}$ with probability $\pi$, where for the ith case,

$$
\begin{aligned}
& \pi_{\mathrm{i}}=\frac{\exp \left(\mathrm{n}_{\mathfrak{i}}\right)}{1+\exp \left(\mathrm{n}_{\mathfrak{i}}\right)} \\
& \text { Or } \\
& \ln \frac{\pi_{\mathfrak{i}}}{1-\pi_{\mathfrak{i}}}=\mathfrak{n}_{\mathfrak{i}}=\mathcal{X i} \mathcal{B}
\end{aligned}
$$

Hence, the likelihood function 1 for $n$ observations $y_{1} \ldots$... $\mathrm{y}_{\mathrm{n}}$ with probabilities $\pi_{1} \ldots \pi_{n}$ and case weights $\mathrm{W}_{1} \ldots, \mathrm{W}_{\mathrm{n}}$ can be written as

$1=\prod_{\mathfrak{i}-1}^{\eta} \pi_{\mathfrak{i}}^{\mathcal{W i} \mathcal{Y i}_{i}}\left(1-\pi_{\mathfrak{i}}\right)^{\mathcal{W i}(1-\mathcal{Y i})}$

It follows that the logarithm of $l$ is

$$
\mathcal{L}=\ln (1)=\sum_{\mathrm{i}=1}^{\mathrm{n}}\left(\mathcal{W}_{\mathrm{i}} \mathcal{Y}_{\mathrm{i}} \ln \left(\pi_{\mathrm{i}}\right)+\mathcal{W}_{\mathrm{i}}\left(1-\mathcal{Y}_{\mathrm{i}}\right) \ln \left(1-\pi_{\mathrm{i}}\right)\right)
$$

and the derivative of $\mathrm{L}$ with respect to $\beta j$ is

$$
\mathcal{L}^{*} \mathcal{X}_{\mathrm{i}}=\frac{\partial \mathcal{L}}{\partial \beta_{j}}=\sum_{\mathrm{i}=1}^{\mathrm{n}} \mathcal{W}_{\mathrm{i}}\left(\mathcal{Y}_{\mathrm{i}}-\pi_{\mathrm{i}}\right)
$$

The $\beta$ tells us how a one-unit increase in the independent variable increases the log-odds of being higher than category $j$ (due to the negative sign). Because, this $\beta$ is not indexed by $j$ it is assumed that the one-unit increase affects the log-odds the same regardless of which cutpoint we are considering. The dependent variable in the model is acceptance (willingness to pay) of consumers to purchase "Bisr" if commercially produced and made available on the market. Independent variables that are hypothesized to affect consumer's decision in this respect are identified. They are categorized in to sociodemographic variables (respondent's age, gender, level of education, marital status, emirate of residence, amount of personal income); experience of date consumption (eating date and frequency of consumption in a week); knowledge about the stages of date fruit and use of the dates as well as experience of "Bisr" consumption; and perception of certain features of "Bisr" (appearance, smell, color, taste and flavor).

\section{RESULTS AND DISCUSSION}

The results and discussion section is divided into the descriptive analysis of the data and the logit model analysis with sensory variables.

\section{Consumers' profile}

We conducted an exploratory research involving 276 consumers in which data on socio-demographic characteristics and ways of date consumption were collected. The study population is the UAE consumers. Respondents were randomly selected from the United Arab Emirates University (UAEU) students, staff, faculty members as well as consumers from the $\mathrm{Al}$ Ain city. For logistics reason and practical convenience, the large share of the respondents is drawn from the UAE university community (students, faculty and staff). As the UAE university students come from all of the country, it can be said that this study survey was addressed to all over the UAE. Relevant demographic and socio-economic data and information of individual respondents were collected and documented. Participants were predominantly women $(94 \%)$ while males account for $6 \%$ only (Annex Tables 1-4). The high participation of females in the study can be attributed to their higher willingness to take part in the study. This reflects also the gender distribution of the UAEU students' population.

In terms of age distribution, $43 \%$ of the respondents are less than 21 years of age and 50\% are between 21-30 years old. Regarding the marital status, $22 \%$ of the respondents are married while $77 \%$ are single. The level of education of $71 \%$ of the respondents is undergraduate university college while bachelor and graduate degree holders are 16\% and $6.2 \%$ of the sample, respectively. Those who are at the high school level of education account for $7 \%$.

Occupation wise, $85 \%$ of the respondents are students while university faculty members and staff account for 
$0.7 \%$ and $4 \%$, respectively. Respondents with other occupations are $11 \%$. Sixty-five percent of the respondents are residents of the Abu Dhabi emirate while the remaining $35 \%$ are distributed over the other emirates.

The average monthly income of respondents is 8,700 Dirhams; and the income ranges from lowest of 2,500 Dirhams to highest of 25,000 Dirhams (see Table 1). A frequency distribution of the monthly income of respondents shows that $52 \%$ earn 2,500 Dirhams while 26\% earn 10,000 Dirhams. Another 12\% earn 20,000 Dirhams while 9\% earn 25,000 Dirhams.

\section{Results of sensory evaluation}

Respondents were asked about how frequently they eat date. Two percent replied they do not eat date. Those who eat once in a week account for $36 \%$ of the sample, while $30 \%, 11 \%$ and $21 \%$ of the respondents say they eat dates once, three times, five time and seven times a week (see Fig. 2). Respondents were also asked whether they are aware of the ripening stages of dates locally known as "Bisr", rutab and tamer. Accordingly, $90 \%$ of the respondents say they know these ripening stages while $10 \%$ do not know about these stages. A little over $40 \%$ of the respondents say they have experience of eating "Bisr" while $57 \%$ have not eaten "Bisr". This may be due to the fact that not all consumers eat date fruit at specific repining stage; rather the consumer market avails date fruits at specific or most common ripening stages like the final stage.

Respondents were requested to evaluate "Bisr" taking various aspects (i.e. sensory characteristics), namely appearance, aroma (smell), colour, taste and flavor (Annex Table 5). The response is expressing feelings in a scale ranging from 'dislike extremely' to 'like extremely, including indifference i.e. neither like nor dislike. Some $5 \%$ of the respondents said that they extremely dislike the appearance of the "Bisr" they were presented with while $8.3 \%$ extremely like it. Another $17.3 \%$ are indifferent to the appearance. In summary, while $28 \%$ did not like the appearance, $55 \%$ like it. Attitude to appearance of the "Bisr" seems to influence respondents' acceptance of "Bisr" if commercially available. Two percent of the respondents extremely dislike the smell of the sample of "Bisr" while 7.5\% extremely like it. $27 \%$ are indifferent to the smell. In summary, while 13\% did not like the smell, $60 \%$ like it. Two percent of the respondents extremely disliked the color of "Bisr" sample, while $8.7 \%$ extremely like it and $12 \%$ were indifferent about the color. In general, $20 \%$ of respondents dislike the color while $70 \%$ like it.

Five percent of the respondents extremely dislike the taste of the "Bisr" sample while 13\% extremely like it.

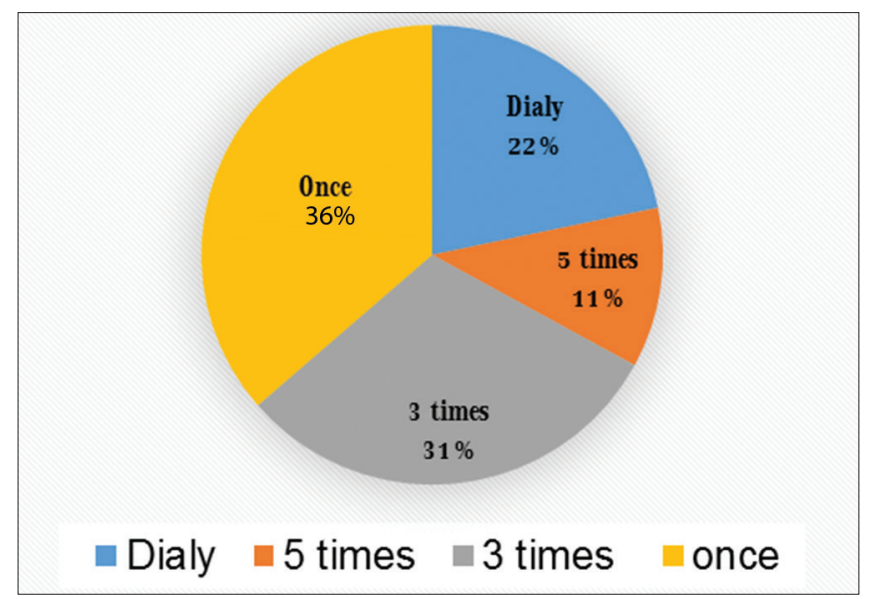

Fig 2. Frequency of eating dates in a week $(\mathrm{N}=267)$.

Table 1: Descriptive statistics of dependent and explanatory variables ( $\mathrm{N}=276)$. (1 $\mathrm{Dhs}=0.273 \mathrm{USD})$

\begin{tabular}{|c|c|c|c|c|c|c|}
\hline $\begin{array}{l}\text { Dependent variable/Explanatory } \\
\text { variables }\end{array}$ & Mean & Median & Mode & $\begin{array}{l}\text { Standard } \\
\text { deviation }\end{array}$ & $\begin{array}{l}\text { Coefficient of variable (CV) } \\
=(\text { Standard } / \text { mean })^{*} 100\end{array}$ & $\begin{array}{l}\text { Description of } \\
\text { median category }\end{array}$ \\
\hline $\begin{array}{l}\text { Purchase 'Bisr' if commercially } \\
\text { available }\end{array}$ & 0.69 & 1.00 & 1 & 0.462 & $67 \%$ & $\begin{array}{l}1=\text { Accept; } 0=\text { Do not } \\
\text { accept }\end{array}$ \\
\hline Gender & 0.94 & 1.00 & 1 & 0.234 & $25 \%$ & Male $=0 ;$ Female $=1$ \\
\hline Age & 1.78 & 2.00 & 2 & 0.840 & $47 \%$ & 21-24 years old \\
\hline Marital & 1.80 & 2.00 & 2 & 0.438 & $24 \%$ & Single \\
\hline Education & 2.24 & 2.00 & 2 & 0.714 & $32 \%$ & College degree \\
\hline Monthly household income & 8704 & 2,500 & 2,500 & 7817.38 & $90 \%$ & $\begin{array}{l}\text { More than } \\
2,500-10,000 \text { Dhs }\end{array}$ \\
\hline Emirates of residency & 2.03 & 1.00 & 1 & 1.671 & $82 \%$ & Abu Dhabi Emirate \\
\hline Frequency of eating dates & 3.26 & 3.00 & 1 & 2.330 & $71 \%$ & $\begin{array}{l}\text { Daily - more than } \\
5 \text { times a week }\end{array}$ \\
\hline Knowledge of dates stages & 0.89 & 1.00 & 1 & 0.319 & $36 \%$ & Yes $=1, \mathrm{No}=0$ \\
\hline Eats "Bisr" dates & 0.46 & 0.00 & 0 & 0.720 & $157 \%$ & $\mathrm{Yes}=1, \mathrm{No}=0$ \\
\hline Appearance & 5.58 & 6.00 & 7 & 2.059 & $37 \%$ & 6=like slightly \\
\hline Smell (Aroma) & 5.94 & 6.00 & 5 & 1.682 & $28 \%$ & $6=$ like slightly \\
\hline Color & 6.03 & 6.00 & 7 & 1.823 & $30 \%$ & $6=$ like slightly \\
\hline Taste & 6.17 & 6.50 & 7 & 2.038 & $33 \%$ & 7=like moderately \\
\hline Flavor & 6.24 & 7.00 & 7 & 2.089 & $33 \%$ & 7=like moderately \\
\hline
\end{tabular}


A small percentage, $7 \%$, was indifferent to the taste they experienced. Overall, $73 \%$ of the respondents liked the taste (at varying degree) while $20 \%$ did not like the taste. In terms of evaluating the flavor of the sample, $5 \%$ extremely disliked the flavor while 13\% extremely like the flavor; another $8 \%$ were indifferent about the flavor. Overall, $75 \%$ of the respondents liked the flavor and $20 \%$ did not like. Respondents were also asked whether they would buy "Bisr" if commercially produced and made available on the market. Accordingly, over two-third of the respondents (70\% of the 276-sample survey) have reported that they are willing to buy "Bisr" if commercially available while close to one-third said they will not buy "Bisr" if commercially made available (see Fig. 3).

The result may signal that there is an opportunity to develop a "Bisr" dates and promote to the consumers to add economic value and diversify the sources of benefit from date production in the UAE. As discussed above, specific sensory characteristics of Bisr, color, appearance, and flavor, that influence their purchasing decision should be taken into consideration when developing and availing this product to consumers.

\section{Logit model analysis with sensory variables results}

A logit model which is a suitable econometric model to use when the dependent variable is taking the categorical (binary) format is estimated to identify factors that influence consumers' decision to accept "Bisr" if commercially made available. Socio-demographic variables, experience of date consumption (eating date and frequency of consumption in a week); knowledge about stages of date fruit as well as experience of "Bisr" consumption; and perception of certain features of "Bisr" (appearance, smell, color, taste and flavor) are predictor variables included in the model. The results of the logit model are presented in Table 2. The result shows that the model is fit to (appropriate for) the data. The maximum likelihood estimation worked well and convergence is obtained within 5 iterations. The results on the two measures show that the proportion of unaccounted for variance is smaller i.e. 0.277 and 0.391 , respectively, showing that the independent variables in the model explain the larger portion of the variation in the dependent variable. The model result shows that 178 cases are observed to have accepted the "Bisr" ( $Y=$ 1) and correctly predicted to have accepted, while 45 cases are observed to have rejected "Bisr" and also predicted to reject. The Model has an overall 69\% correct prediction of the dependent variable i.e. the acceptance of "Bisr".

The Wald chi-square test and associated probabilities provide the measures whether the coefficients and constant term are different from zero or not. Table 2 shows the variables in the equation where the dependent variable is

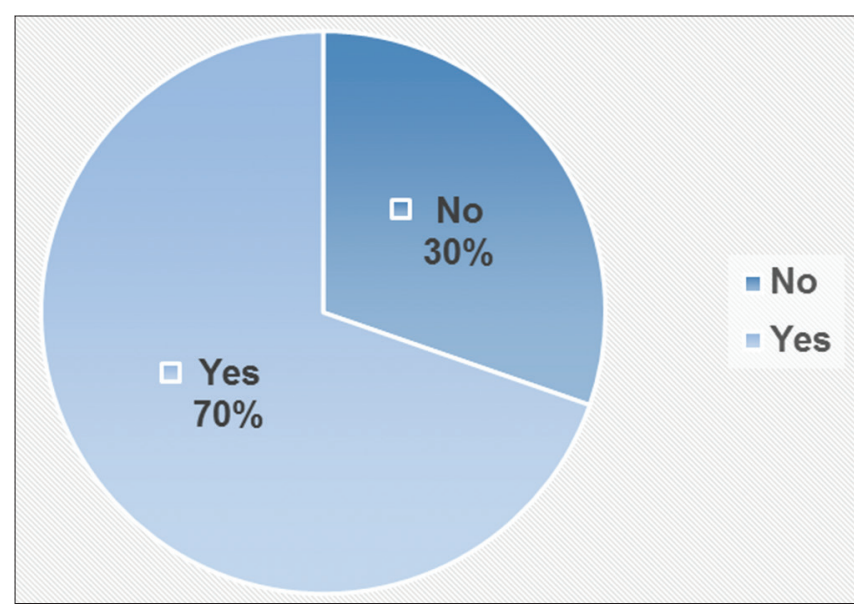

Fig 3. Willingness to buy 'Bisr' if commercially made available ( $N=276)$.

purchase Bisr if commercially made available. The second column in the results table shows the logit coefficients in the log-odds units. Their interpretation needs estimation of the predicted probability (odds ratios) of the dependent variable $(Y=1)$. The last Colum shows the exponentiation of the Beta coefficient and is an odds ratio. The figures are the odds of $\mathrm{Y}=1$ when $\mathrm{X}$ increases by 1 unit. These are the exp. (logit coefficients). They are interpreted in such a way that if the OR (odds ratio) $>1$ then the odds of $Y=1$ increases; If the $\mathrm{OR}<1$, then the odds of $\mathrm{Y}=1$ decreases. A logistic regression model allows to establish a relationship between a binary outcome variable and a group of predictor variables. It models the logit-transformed probability as a linear relationship with the predictor variables.

The results show that among the independent (predictor variables), the level of education, knowledge of stages of date fruits, having previous experience of eating "Bisr", consumers' perceptions of the appearance, smell and color significantly influence the decision to accept and buy (willingness to pay for) "Bisr" if commercially produced and made available. In other words, the likelihood of accepting "Bisr" and purchasing it, if made commercially available, increases with level of education, knowledge of the date fruits stage, experience of eating "Bisr", appearance and color of "Bisr". Other variables such as gender, age, marital status, monthly personal income, region of residence do not have significant effect on consumers' decision in this respect.

The resulting prediction equation is:

$\log \left((\mathrm{p}) /(1-\mathrm{p})=\mathrm{b}_{0}\right)+\mathrm{b}_{1}{ }^{*} \mathrm{x}_{1}+\mathrm{b}_{2}{ }^{*} \mathrm{x}_{2}+\mathrm{b}_{3}{ }^{*} \mathrm{x}_{3}+\mathrm{b}_{4}{ }^{*} \mathrm{x}_{4}$

Where $\mathrm{p}$ is the probability of accepting and buying "Bisr" if commercially available. This can be expressed in terms of the variables used in the model. The logistic regression equation is: 
Degefa, et al:: Market acceptability of dried dates at the unripe "Bisr" stage in United Arab Emirates

Table 2: Results of Logit model augmented with sensory variables

\begin{tabular}{|c|c|c|c|c|c|c|}
\hline Explanatory variables & Beta coefficient & Standard error & Wald test & $\begin{array}{l}\text { Degrees of } \\
\text { freedom (d.f.) }\end{array}$ & Significance & Expected value (B) \\
\hline Gender & 0.024 & 0.728 & 0.001 & 1 & 0.974 & 1.024 \\
\hline Age & -0.031 & 0.240 & 0.016 & 1 & 0.899 & 0.970 \\
\hline Marital status & -0.136 & 0.386 & 0.124 & 1 & 0.724 & 0.873 \\
\hline Level of education & 1.114 & 0.334 & 11.114 & 1 & 0.001 & 3.046 \\
\hline $\begin{array}{l}\text { Household monthly } \\
\text { income }\end{array}$ & 0.000 & 0.000 & 0.026 & 1 & 0.872 & 1.000 \\
\hline Emirate of residence & 0.086 & 0.099 & 0.754 & 1 & 0.385 & 1.090 \\
\hline Eating dates, frequency & 0.103 & 0.074 & 1.961 & 1 & 0.161 & 1.109 \\
\hline Knowledge, dates stage & 1.763 & 0.535 & 10.862 & 1 & 0.001 & 5.828 \\
\hline Eating "Bisr" & 1.436 & 0.373 & 14.824 & 1 & 0.000 & 4.206 \\
\hline Appearance & 0.171 & 0.119 & 2.074 & 1 & 0.150 & 1.186 \\
\hline Smell (Aroma) & -0.384 & 0.147 & 6.860 & 1 & 0.009 & 0.681 \\
\hline Color & 0.318 & 0.118 & 7.291 & 1 & 0.007 & 1.375 \\
\hline Taste & -0.278 & 0.228 & 1.481 & 1 & 0.224 & 0.757 \\
\hline Flavor & 0.665 & 0.230 & 8.337 & 1 & 0.004 & 1.944 \\
\hline Constant & -6.772 & 1.741 & 15.123 & & 0.000 & 0.001 \\
\hline
\end{tabular}

d.f. (degrees of freedom) is the degrees of freedom for the Wald chi-square test for each variable in the model

$\log (p / 1-p)=-6.77+1.11 *$ education $+1.76 *$ datessatge + $1.44 *$ eat "Bisr"- $0.38 *$ Smell +0.32 *color $+0.67 *$ flavor.

These estimates show the amount of increase/decrease in the predicted log odds of accepting or willing to pay for "Bisr" = 1 that would be predicted by a 1 unit increase/decrease in the predictor, while keeping all other predictors constant. For instance, an increase in the level of education by 1 increases/changes the odds of accepting "Bisr" by $11 \%$ while the increase in the frequency of eating dates by 1 unit changes it by $44 \%$. However, since these coefficients that are in log-odds units are difficult to interpret, they are converted to odds ratios by finding their exponentials. The last column in the tables provides ' $\operatorname{Exp}(\mathrm{B})$ ' of the estimates. The fitted model result shows that holding other factors constant, the odds ratios of accepting "Bisr" for an educated person is 3.05. In other words, an increase in the level of education by a unit, holding other factors constant, increases the chance of accepting "Bisr" by $200 \%$. Similarly, holding other factors constant the probability that someone who has a knowledge of the stage of date fruits accepts "Bisr" more than the one without such a knowledge is $480 \%$ (or close to five-fold).

The results imply the positive impacts of the general awareness and education programs through media communication to consumers about the growth and ripening process of date fruits. Having an experience of eating "Bisr" increases the chance of accepting "Bisr" by $320 \%$ compared to a person that has not experienced it, given other factors constant. Promotional activities of displaying and introducing "Bisr" to consumers and encouraging them to test or eat would increase its marketability. A bad or unpleasant smell of "Bisr" would reduce its chance of marketability by $32 \%$, keeping other factors constant. This implies that care should be taken in ensuring the hygienic condition while processing and packaging "Bisr" destined for market on a commercial scale. An attractive color would increase the chance of acceptance of Bisr by 38\% while a distinctive test (flavor) will increase acceptability by $95 \%$.

\section{CONCLUSION}

The dates produce form of dates the project has dealt with is called "Bisr". The study analyzes product taste, quality and investigates factors that affect the consumers' willingness to pay for the product. The main objective of the analysis of consumers' perception, acceptance and their attitude towards the "Bisr" is to identify the characteristics of the final product that are important to the overall liking and marketability of the product. Data was collected in 2014 from a sample of 276 randomly selected respondents - United Arab Emirates University (UAEU) students, workers and other consumers in the city of Al Ain. Respondents tasted the "Bisr" and expressed their evaluation of the taste, color, shape, aroma or flavor of the two samples. Over two-third of the respondents $(70 \%)$ have reported that they would buy "Bisr" if it is commercially available while close to one-third said they will not buy "Bisr". An ordered logit model is estimated to identify factors that influence consumer's decision to accept "Bisr" if commercially available. The result of the model shows that consumer's level of education, knowledge of stages of date fruits, having previous experience of eating "Bisr", perceptions of the product's 
smell and color significantly influence her/his decision to accept and buy "Bisr". An increase in the level of education by a unit, holding other factors constant, increases the chance of purchasing "Bisr" by two-fold. The probability that someone who has a knowledge of the stage of date fruits accepts "Bisr" more than the one without such a knowledge is very high. It is essential to provide general awareness and education programs through media communication to consumers about the growth and ripening process of date fruits. A bad or unpleasant smell of "Bisr" would reduce its chance of marketability. Use of suitable natural additives may be recommended to overcome this problem of unpleasant smell. Hence, hygienic care should be given in producing and availing a clean product to consumers. Attractive color and flavor also increase the chance of marketability and acceptability of "Bisr" by consumers. and hence precise control of "Bisr" processing is essential to retain the natural fruit color.

\section{ACKNOWLEDGEMENT}

We would like to extend our gratitude to Prof. Afaf Kamal for initiating and undertaking a research project entitled 'Broadning Innovative Solution Rooms for DATES (BISR.DATES). The project was funded under the UAEU $3^{\text {rd }}$ Research Grant Competition. This manuscript is developed as part of the project with the aim of addressing the knowledge needed in product development strategy from the demand side as related to the key factors that affect the consumers' decision and marketability of the product.

\section{Authors' contributions}

Authors equally contributed towards the development of the manuscript during the research, analyses of results and report writing. The first author took the lead towards writing the first and final drafts of the article.

\section{REFERENCES}

Abu Dhabi Food Control Authority. 2015. Delicious Dates - Available All Year Round. Available from: http://www.adfca.ae/English/ MediaCenter/Publications/Documents/ROTAB-web-e.pdf.

Al-Farsi, M. A. and C. Y. Lee. 2008. Nutritional and functional properties of dates: A review. Crit. Rev. Food Sci. Nutr. 48: 877-887.

Al-Orf, S. M., H. M. A. Mona, A. Norah, A. Huda, D. Asma and D. Sumayyah. 2012. Review: Nutritional properties and benefits of the date fruits (Phoenix dactylifera L.). Bull. Natl. Nutr. Inst. Arab Repub. Egypt. 39: 97.

Chandrasekaran, M. and A. H. Bahkali. 2013. Valorization of date palm (Phoenix dactylifera) fruit processing by-products and wastes using bioprocess technology - Review. Saudi J. Biol. Sci. 20(2): 105-120.

Costell, E., A. Tárrega and S. Bayarri. 2010. Food acceptance: The role of consumer perception and attitudes. Chem. Precept. 3: 42-50.

Cox, D. R. and E. J. Snell. 1989. Analysis of Secondary Data. $2^{\text {nd }}$ ed. Chapman and Hall/CRC, USA.

El-Juhany, L. I. 2010. Degradation of date palm trees and date production in Arab countries: Causes and potential rehabilitation. Aust J. Basic Appl. Sci. 4(8): 3998-4010.

Food and Agriculture Organization of the United Nations. 2016. FAOSTAT Statistical Database. Available from: http://www.fao. org/faostat/en/\#data/QC/visualize.

Ghnimi, S., S. Ummer, A. Karim and A. Kamal-Eldin. 2017. Date fruit (Phoenix dactylifera L.): An underutilized food seeking industrial valorization. NFS J. 6: 1-10.

Lusk, J. L., J. Roosen and A. Bieberstein. 2014. Consumer acceptance of new food technologies: Causes and roots of controversies. Annu. Rev. Resour. Economics. 6: 381-405.

Nasir, M. U., S. Hussain, S. Jabbar, F. Rashid, N. Khalid and A. A. Mehmood. 2015. A review of the nutritional content, functional properties and medicinal potential of dates. Sci. Lett. 3(1): 17-22.

Shafiei, M., K. Karimi and M. J. Taherzadeh. 2010. Palm date fibers: Analysis and enzymatic hydrolysis. Int. J. Mol. Sci. 11: 4285-4296.

Staff Report. 2011. UAE Dominates World Dates Trade. Khaleej Times Online. March $5^{\text {th }}$. Available from: http://www.khaleejtimes. com/business/local/uae-dominates-world-dates-trade. [Last accessed on 2015 May 31]. 


\section{ANNEX}

Annex Table 1: Summary of survey results on socio-demographic characteristics $(\mathrm{N}=\mathbf{2 7 6})$

\begin{tabular}{|c|c|c|}
\hline Variable & Metric & Frequency (\%) \\
\hline \multirow[t]{3}{*}{ Gender } & Male & $16(5.8)$ \\
\hline & Female & $260(94.2)$ \\
\hline & Total & $276(100.0)$ \\
\hline \multirow[t]{5}{*}{ Age (year) } & $16-20$ & $117(42.4)$ \\
\hline & $21-24$ & $122(44.2)$ \\
\hline & $25-30$ & $19(6.9)$ \\
\hline & 31 and above & $18(6.5)$ \\
\hline & Total & $276(100.0)$ \\
\hline \multirow[t]{4}{*}{ Marital status } & Married & $60(21.7)$ \\
\hline & Single & $212(76.8)$ \\
\hline & Divorced & $4(1.4)$ \\
\hline & Total & $276(100.0)$ \\
\hline \multirow[t]{6}{*}{ Education } & High school & $18(6.5)$ \\
\hline & Undergraduate & $195(70.7)$ \\
\hline & Bachelor & 45 (16.3) \\
\hline & Graduate & $17(6.2)$ \\
\hline & Other & $1(0.4)$ \\
\hline & Total & $276(100.0)$ \\
\hline \multirow[t]{5}{*}{ Occupation } & Faculty, UAEU & $2(0.7)$ \\
\hline & Staff member, UAEU & $11(4.0)$ \\
\hline & Student, UAEU & $232(84.1)$ \\
\hline & Other & $31(11.3)$ \\
\hline & Total & $276(100.0)$ \\
\hline \multirow[t]{10}{*}{ Field of study } & Business and economics & $45(16.3)$ \\
\hline & $\begin{array}{l}\text { Humanities and social } \\
\text { sciences }\end{array}$ & $44(15.9)$ \\
\hline & IT & $23(8.3)$ \\
\hline & Engineering & $28(10.1)$ \\
\hline & Education & $21(7.6)$ \\
\hline & Law & $9(3.3)$ \\
\hline & Food and agriculture & $46(16.7)$ \\
\hline & Science & $29(10.5)$ \\
\hline & Medicine and health & $2(0.7)$ \\
\hline & Others & $29(10.5)$ \\
\hline \multirow{8}{*}{$\begin{array}{l}\text { Emirate of } \\
\text { residence }\end{array}$} & Abu Dhabi & $180(65.2)$ \\
\hline & Dubai & $20(7.2)$ \\
\hline & Sharjah & $23(8.3)$ \\
\hline & Ras Al Khaima & $21(7.6)$ \\
\hline & Um Al Quwaim & 7 (2.5) \\
\hline & Ajman & $23(8.3)$ \\
\hline & Fujairah & $2(0.7)$ \\
\hline & Total & 276 (100.0) \\
\hline
\end{tabular}

Annex Table 2: Summary of survey results: Income and frequency of eating date $(\mathrm{N}=\mathbf{2 7 6})$

\begin{tabular}{lccccc}
\hline Variable & N & Mean & Standard & Minimum & Maximum \\
\hline Monthly income (Dirham) & 276 & 8705 & 7817.389 & 0 & 25000 \\
Frequency of eating date (days/week) & 276 & 3.26 & 2.330 & 0 & 7 \\
\hline
\end{tabular}


Anne Table 3: Summary of survey results: Knowledge, experience and attitude towards "Bisr" $(\mathrm{N}=276)$

\begin{tabular}{|c|c|c|c|}
\hline Variable & Metric & Frequency (\%) & Cumulative \% \\
\hline \multirow{3}{*}{$\begin{array}{l}\text { Knowledge of } \\
\text { date stages }\end{array}$} & No & $30(10.9)$ & 10.9 \\
\hline & Yes & $245(88.8)$ & 99.6 \\
\hline & Total & $276(100.0)$ & \\
\hline \multirow[t]{3}{*}{ Eat "Bisr" } & No & $158(57.2)$ & 57.2 \\
\hline & Yes & $116(42.0)$ & 99.3 \\
\hline & Total & $276(100.0)$ & \\
\hline \multirow{3}{*}{$\begin{array}{l}\text { Knowledge of } \\
\text { uses of "Bisr" }\end{array}$} & No & $188(68.1)$ & 68.1 \\
\hline & Yes & $88(31.9)$ & 100.0 \\
\hline & Total & $276(100.0)$ & \\
\hline \multirow{12}{*}{$\begin{array}{l}\text { Evaluation, } \\
\text { appearance of } \\
\text { "Bisr" }\end{array}$} & $\begin{array}{l}\text { Dislike } \\
\text { extremely }\end{array}$ & $14(5.1)$ & 5.1 \\
\hline & $\begin{array}{l}\text { Dislike } \\
\text { very much }\end{array}$ & $12(4.3)$ & 9.4 \\
\hline & $\begin{array}{l}\text { Dislike } \\
\text { moderately }\end{array}$ & $15(5.4)$ & 14.9 \\
\hline & $\begin{array}{l}\text { Dislike } \\
\text { slightly }\end{array}$ & $36(13.0)$ & 27.9 \\
\hline & $\begin{array}{l}\text { Subtotal } \\
\text { dislike }\end{array}$ & 77 (27.9) & 27.9 \\
\hline & $\begin{array}{l}\text { Neither } \\
\text { like nor } \\
\text { dislike }\end{array}$ & 48 (17.4) & 45.3 \\
\hline & $\begin{array}{l}\text { Like } \\
\text { slightly }\end{array}$ & $52(18.8)$ & 64.1 \\
\hline & $\begin{array}{l}\text { Like } \\
\text { moderately }\end{array}$ & 55 (19.9) & 84.1 \\
\hline & $\begin{array}{l}\text { Like very } \\
\text { much }\end{array}$ & $21(7.6)$ & 91.7 \\
\hline & $\begin{array}{l}\text { Like } \\
\text { extremely }\end{array}$ & $23(8.3)$ & 100.0 \\
\hline & $\begin{array}{l}\text { Subtotal } \\
\text { like }\end{array}$ & $151(54.7)$ & \\
\hline & Total & $276(100.0)$ & \\
\hline
\end{tabular}

Annex Table 4: Summary of survey results: Acceptance of "Bisr" (N=276)

\begin{tabular}{llc}
\hline Variable & Response & Frequency (\%) \\
\hline $\begin{array}{l}\text { Would buy "Bisr" if commercially } \\
\text { available }\end{array}$ & No & $85(30.8)$ \\
& & \\
& Yes & $191(69.2)$ \\
& Total & $276(100.0)$ \\
\hline
\end{tabular}


Annex Table 5: Sensory results

\begin{tabular}{|c|c|c|c|}
\hline Variable & Metric & Frequency (\%) & Cumulative \% \\
\hline \multirow[t]{12}{*}{ Evaluation, smell of "Bisr" } & Dislike extremely & $6(2.2)$ & 2.2 \\
\hline & Dislike very much & $5(1.8)$ & 4.0 \\
\hline & Dislike moderately & $10(3.6)$ & 7.6 \\
\hline & Dislike slightly & $13(4.7)$ & 12.3 \\
\hline & Subtotal dislike & $34(12.3)$ & 26.1 \\
\hline & Neither like nor dislike & $74(26.8)$ & 39.1 \\
\hline & Like slightly & $69(25.0)$ & 64.1 \\
\hline & Like moderately & $56(20.3)$ & 84.4 \\
\hline & Like very much & $22(8.0)$ & 92.4 \\
\hline & Like extremely & $21(7.6)$ & 100.0 \\
\hline & Subtotal like & $168(60.9)$ & 340.9 \\
\hline & Total & $276(100.0)$ & \\
\hline \multirow[t]{12}{*}{ Evaluation, color of "Bisr" } & Dislike extremely & $6(2.2)$ & 2.2 \\
\hline & Dislike very much & $7(2.5)$ & 4.7 \\
\hline & Dislike moderately & $14(5.1)$ & 9.8 \\
\hline & Dislike slightly & $27(9.8)$ & 19.6 \\
\hline & Subtotal dislike & $54(19.6)$ & 19.6 \\
\hline & Neither like nor dislike & $32(11.6)$ & 31.2 \\
\hline & Like slightly & $68(24.6)$ & 55.8 \\
\hline & Like moderately & $74(26.8)$ & 82.6 \\
\hline & Like very much & $24(8.7)$ & 91.3 \\
\hline & Like extremely & $24(8.7)$ & 100.0 \\
\hline & Subtotal like & $190(68.8)$ & \\
\hline & Total & $276(100.0)$ & \\
\hline \multirow[t]{12}{*}{ Evaluation, taste of "Bisr" } & Dislike extremely & $13(4.7)$ & 4.7 \\
\hline & Dislike very much & $7(2.5)$ & 7.2 \\
\hline & Dislike moderately & 9 (3.3) & 10.5 \\
\hline & Dislike slightly & $26(9.4)$ & 19.9 \\
\hline & Subtotal dislike & $55(19.9)$ & 19.9 \\
\hline & Neither like nor dislike & $20(7.2)$ & 27.2 \\
\hline & Like slightly & $63(22.8)$ & 50.0 \\
\hline & Like moderately & $73(26.4)$ & 76.4 \\
\hline & Like very much & $30(10.9)$ & 87.3 \\
\hline & Like extremely & $35(12.7)$ & 100.0 \\
\hline & Subtotal like & $201(72.8)$ & \\
\hline & Total & $276(100.0)$ & \\
\hline \multirow[t]{12}{*}{ Evaluation, flavor of "Bisr" } & Dislike extremely & $14(5.1)$ & 5.1 \\
\hline & Dislike very much & $10(3.6)$ & 8.7 \\
\hline & Dislike moderately & $8(2.9)$ & 11.6 \\
\hline & Dislike slightly & $18(6.5)$ & 18.1 \\
\hline & Subtotal dislike & $50(18.1)$ & 18.1 \\
\hline & Neither like nor dislike & $21(7.6)$ & 25.7 \\
\hline & Like slightly & $55(19.9)$ & 45.7 \\
\hline & Like moderately & $80(29.0)$ & 74.6 \\
\hline & Like very much & $34(12.3)$ & 87.0 \\
\hline & Like extremely & $36(13.0)$ & 100.0 \\
\hline & Subtotal like & $205(74.3)$ & \\
\hline & Total & $276(100.0)$ & \\
\hline \multirow[t]{3}{*}{ Eat date } & No & $10(3.6)$ & 3.6 \\
\hline & Yes & $266(96.4)$ & 100.0 \\
\hline & Total & $276(100.0)$ & \\
\hline
\end{tabular}

